\title{
Article \\ Challenges in the Electromagnetic Design of Multiphase Machines: Winding and Equivalent Circuit Parameters
}

\author{
Jan Laksar (D), Radek Cermak * and Karel Hruska (D) \\ Research and Innovation Centre for Electrical Engineering, Faculty of Electrical Engineering, \\ University of West Bohemia, Univerzitni 26, 30100 Pilsen, Czech Republic; laksar@fel.zcu.cz (J.L.); \\ khruska@fel.zcu.cz (K.H.) \\ * Correspondence: radek@fel.zcu.cz
}

check for

updates

Citation: Laksar, J.; Cermak, R.;

Hruska, K. Challenges in the

Electromagnetic Design of

Multiphase Machines: Winding and

Equivalent Circuit Parameters.

Energies 2021, 14, 7335.

https: / /doi.org/10.3390/

en14217335

Academic Editors: Youguang Guo,

Gang Lei and Xin Ba

Received: 27 September 2021

Accepted: 28 October 2021

Published: 4 November 2021

Publisher's Note: MDPI stays neutral with regard to jurisdictional claims in published maps and institutional affiliations.

Copyright: (c) 2021 by the authors. Licensee MDPI, Basel, Switzerland. This article is an open access article distributed under the terms and conditions of the Creative Commons Attribution (CC BY) license (https:/ / creativecommons.org/licenses/by/ $4.0 /)$.

\begin{abstract}
The usage of multiphase electrical drives expands the operation possibilities of electrical machines and opens new directions of research on inverter-fed electrical machines. With an increasing number of phases, the standard approach of the electromagnetic design of machines has to be generalized to $m$-phase systems, which is not usually respected in the literature focused on electric machine design, and it is rarely published. This paper summarizes the specific problems linked with the design of machines with different numbers of phases, focusing on the winding design and the calculation of equivalent circuit parameters. In addition to the direct effect of different numbers of phases, the impact of injecting higher order time harmonic components on the electromagnetic design of electric machines is analyzed. The obtained analytical results are verified by the measurement of a nine-phase experimental induction motor.
\end{abstract}

Keywords: multiphase machines; machine design; winding; inductance; higher order harmonic component injection

\section{Introduction}

The ever-increasing public and political interest in the environment in the last two decades has had a significant impact on the global transportation industry. New emerging visions, such as the Green Deal in Europe, plan to reduce harmful global emissions in the atmosphere caused by transportation by $90 \%$ by 2050 . To meet the increasing emission requirements, personal, public, and special vehicle manufacturers are replacing their internal-combustion-engine-based drives with battery-powered electric machines. Since this type of drive is not dependent on the number of phases of the power system, it is possible to use electric machines with a number of phases, $m$, greater than three, i.e., multiphase machines.

Although the concept of multiphase drives dates back to the middle of the 20th century, they are not commonly used and only a few manufacturers such as DANA TM4 [1] or Aselsan [2,3] offer them as a solution for electric vehicles. However, in recent decades the amount of publications dealing with multiphase machines has increased. The graph in Figure 1 shows the total number of publications and the number of publications in a five-year period in one of most renowned databases (IEEE Xplore), searched for using the keywords "multiphase machines". Based on this development, more frequent use of multiphase machines and publications dealing with them can be expected in the future.

The comparison of multiphase and three-phase machines has been the subject of many scientific publications. Table 1 shows the most important advantages and differences between the two systems presented in $[4,5]$. In addition to the advantages that benefit from the higher number of phases (lower vibration, lower power per phase, etc.), the multiphase machines have a feature that is generally referred to in the literature as additional degrees of freedom. This feature has already been described in detail in [6-8], and its greatest benefits are the possibility of increasing the power density due to harmonic injection and 
the possibility of changing the number of pole pairs without winding switch-over. These benefits are possible because some of the time harmonics create a different number of pole pairs in multiphase winding than the fundamental harmonic does.

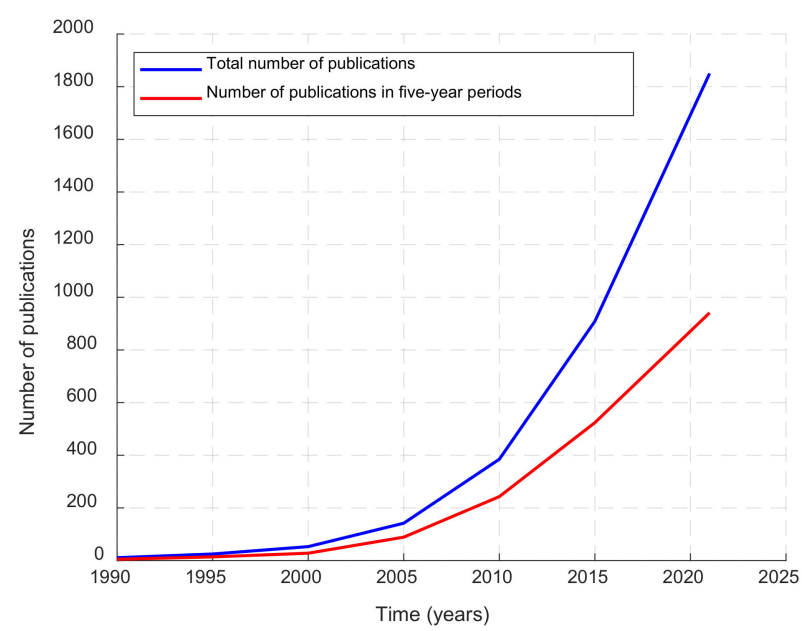

Figure 1. Evolution of published papers dealing with multiphase machines (inspired by [5]).

Table 1. Comparison of multiphase and three-phase electric machines.

\begin{tabular}{|c|c|c|c|c|}
\hline & Three-Phase & Multiphase & $\begin{array}{c}\text { Advantages of } \\
\text { Multiphase Machines }\end{array}$ & $\begin{array}{c}\text { Disadvantages of } \\
\text { Multiphase Machines }\end{array}$ \\
\hline Torque ripple frequency & $6 f_{1}$ & $2 m f_{1}$ & \multirow[b]{2}{*}{ Lower vibrations } & \multirow{3}{*}{$\begin{array}{l}\text { Increases the number of } \\
\text { slots with the same } \\
\text { number of slots per } \\
\text { pole and phase }\end{array}$} \\
\hline $\begin{array}{l}\text { Order of the lowest space } \\
\text { MMF harmonics caused by } \\
\text { stator winding }\end{array}$ & Five and seven & $2 m \pm 1$ & & \\
\hline Winding distribution factor & \multicolumn{2}{|c|}{$\begin{array}{l}\text { Multiphase machines have a higher winding } \\
\text { distribution factor than three-phase machines } \\
\text { with the same number of slots per pole and } \\
\text { phase in addition to the same relative coil pitch }\end{array}$} & $\begin{array}{l}\text { More effective } \\
\text { utilization of stator } \\
\text { winding }\end{array}$ & \\
\hline Power per phase & $P / 3$ & $P / m$ & $\begin{array}{l}\text { Lower demand on } \\
\text { power components }\end{array}$ & $\begin{array}{l}\text { Higher number of } \\
\text { power components }\end{array}$ \\
\hline $\begin{array}{l}\text { Number of different } \\
\text { winding connections }\end{array}$ & Two (star and delta) & $\begin{array}{c}>2 \text { (depends on } \\
\text { number of phases) }\end{array}$ & $\begin{array}{l}\text { Greater connection } \\
\text { variability and } \\
\text { possibility to increase } \\
\text { phase voltages }\end{array}$ & $\begin{array}{l}\text { Each winding } \\
\text { connection acts } \\
\text { different with higher } \\
\text { harmonics }\end{array}$ \\
\hline Harmonic injection & $\begin{array}{l}\text { Only with a } \\
\text { non-rotating } \\
\text { component }\end{array}$ & $\begin{array}{l}\text { Possible with higher } \\
\text { time harmonics }\end{array}$ & $\begin{array}{l}\text { Increases/decreases } \\
\text { peak amplitude/RMS }\end{array}$ & $\begin{array}{l}\text { Possible increase } \\
\text { in iron core losses }\end{array}$ \\
\hline $\begin{array}{l}\text { Changing the number of } \\
\text { pole pairs }\end{array}$ & $\begin{array}{l}\text { Only with Dahlander } \\
\text { winding }\end{array}$ & $\begin{array}{l}\text { Possible with higher } \\
\text { time harmonics }\end{array}$ & $\begin{array}{l}\text { Possibility to change } \\
\text { number of pole pairs } \\
\text { without winding } \\
\text { switch-over }\end{array}$ & $\begin{array}{c}\text { Increase in vibration } \\
\text { and noise due to the } \\
\text { lower numberof } \\
\text { slots per pole and } \\
\text { phase }\end{array}$ \\
\hline $\begin{array}{l}\text { Continued operation after } \\
\text { an open-phase fault }\end{array}$ & No & Yes & & \\
\hline
\end{tabular}

The publications that deal with additional degrees of freedom usually focus on the increase in power density due to harmonic injection and the calculation of the ideal ratio between time harmonics $[7,9,10]$ or design of the specific electric machine that uses the additional degrees of freedom [11-15]. Papers dealing with the calculation of the equivalent circuit parameters are mostly focused on the fundamental harmonic component and they 
describe changes that occur with a higher number of phases $[8,16,17]$. Therefore, our motivation for writing this paper was to provide a detailed description of the general multiphase winding properties and to provide an analytical procedure for the calculation of equivalent circuit parameters, especially the inductance. The presented procedure has been verified by finite element analysis (FEA) and by the measurement of a nine-phase induction machine prototype.

\section{Winding Design of Multiphase Machines}

Balanced, symmetrical, multiphase windings are generally defined by the number of phases, $m$, number of slots, $Q$, number of pole pairs, $p$, number of layers, $2 u$, and by the coil pitch counted in the number of slots, $y_{1 s}$. To ensure the independence of the winding design from the number of poles, the standard three-phase windings are characterized by the number of slots per pole and phase.

$$
q=\frac{Q}{2 p m}
$$

Based on this definition, the number of slots per pole and phase can be used generally as a qualitative criteria to compare windings with a different number of phases. This coefficient has been derived for distributed windings where the number of slots is a multiple of the number of poles; the number of slots per pole and phase is an integer and the winding can be defined as an integral-slot winding.

The number of slots per pole and phase defines the basic geometry of the stator of the machine. The winding can then be modified by the choice of the coil pitch, $y_{1 s}$. For the purpose of qualitative comparison of the influence of the coil pitch of windings with different numbers of slots per pole and phase, the relative coil pitch is defined as:

$$
\beta=\frac{y_{1 s}}{t_{p s}}=\frac{y_{1 s}}{m q}
$$

where $t_{p s}$ is the pole pitch counted in number of slots.

In cases where the number of slots is not a multiple of the number of poles, the fractional-slot winding is obtained and the number of slots per pole and phase is defined as a fraction:

$$
q=\frac{n}{c}
$$

where $n$ and $c$ are indivisible integer numbers defined generally as a numerator and denominator of the number of slots per pole and phase. The special type of winding with $y_{1 s}=1$ is called, in the literature, fractional-slot concentrated winding (FSCW), or tooth winding.

Fractional-slot windings create winding groups with unequal numbers of coils; a balanced winding is created when the machine has at least $c$ poles. The sequence of the winding repeats every $c$ poles, changing the current polarity if $c$ is an odd number. The coil sides of one phase have $n$ unique electrical positions, and the fractional-slot windings can be compared with equivalent integral-slot winding with $q=n$.

The number of layers influences the quality of produced flux linkage and induced voltages (i.e., the content of spatial harmonics); standard windings have $2 u=2$ layers, and in the article the double layer windings are analyzed unless otherwise stated.

The quality of designed winding can be evaluated by the winding factors. The coil pitch shortening causes a decrease in linked flux, and the pitch factor, $k_{y}$, of every spatial harmonic component, $v$, is defined as:

$$
k_{y v}=\sin \left(v \beta \frac{\pi}{2}\right)
$$

The coils are equally distributed around the periphery of the machine; when the number of slots per pole and phase differs from 1, the voltage induced to the coils belonging to 
the same phase has non-zero phase shift and the final induced voltage decreases according to the winding distribution factor, $k_{r}$ :

$$
k_{r v}=\frac{\sin \left(v \frac{\pi}{2 m}\right)}{n \sin \left(v \frac{\pi}{2 m n}\right)}
$$

The negative effects of the discontinuous distribution of the winding can be reduced by the skewing of the slots by usually $y_{s q}=1$ slot; the skewing factor $k_{s q}$ is then defined as:

$$
k_{s q v}=\frac{\sin \left(v \frac{y_{s q}}{m n} \frac{\pi}{2}\right)}{v \frac{y_{s q}}{m n} \frac{\pi}{2}}
$$

The final winding factor $k_{w}$ is then:

$$
k_{w v}=k_{y v} k_{r v} k_{s q v}
$$

\subsection{Limits of the Winding Design}

The design of the three-phase winding has several rules that can be generalized to $m$-phase windings. The denominator $c$ cannot be equal to the multiple of the number of phases, $m$, otherwise the number of unique electrical positions of all windings is equal to $n$ and the winding is unsymmetrical.

Considering only the integer-slot winding, the step curve of produced magnetomotive force, $F_{m}$, is derived in [18] and modified for the winding with $m^{\prime}$, mathematical phases equal to $m^{\prime}=2 m$ :

$$
F_{m \delta}(\xi)=\frac{q I_{m}}{\pi} \sum_{v=1}^{\infty} \frac{1}{v} \sin \left(v \beta \frac{\pi}{2}\right) \frac{\sin \left(v \frac{\pi}{2 m}\right)}{n \sin \left(v \frac{\pi}{2 m n}\right)} \frac{\sin ((v \pm 1) \pi)}{\sin \left(\frac{(v \pm 1)}{m^{\prime}} \pi\right)} \sin \left((\omega t \pm v \xi) \mp(v \pm 1) \frac{\left(m^{\prime}-1\right)}{m^{\prime}} \pi\right)
$$

The equation can be used for a general $2 p$ pole when $\xi$ is used as an electrical spatial position. The magnitude of every harmonic component is defined as:

$$
F_{m v}=\left\{\begin{array}{ll}
\frac{q I_{m}}{\pi} \frac{1}{v} k_{w v} m^{\prime} \cdot(-1)^{k}, & v=k m^{\prime} \mp 1 \\
0 & v \in \mathbb{N} \backslash\left(k m^{\prime} \mp 1\right)
\end{array}, \quad k=0,1,2, \ldots\right.
$$

where $I_{m}$ is the magnitude of the applied symmetrical current. The integer-slot three-phase winding produces spatial harmonics of order $v=1,5,7,11,13, \ldots$ Increasing the number of phases generally increases the order of higher spatial harmonics; the magnitudes of the components of magnetomotive force naturally decrease with an increasing harmonic component order, so the integer-slot windings generally produce spatial harmonics with a lower amplitude. Furthermore, any $m$-phase winding does not generate higher order special harmonics up to the number of phases; thus, the most noticeable harmonic components are reduced simply by an increase in power supply phases.

Increasing the numerator, $n$, theoretically to infinity, the distribution factor can be derived by the usage of L'Hospital's rule as:

$$
k_{r v}=\lim _{n \rightarrow \infty} \frac{\frac{1}{n} \sin \left(v \frac{\pi}{2 m}\right)}{\sin \left(v \frac{\pi}{2 m n}\right)}=\lim _{n \rightarrow \infty} \frac{\frac{-1}{n^{2}} \sin \left(v \frac{\pi}{2 m}\right)}{\frac{-1}{n^{2}} v \frac{\pi}{2 m} \cos \left(v \frac{\pi}{2 m n}\right)}=\frac{m^{\prime}}{v \pi} \sin \left(v \frac{\pi}{m^{\prime}}\right)
$$

The distribution factor curves for different spatial harmonics and number of phases are shown in Figure 2. 


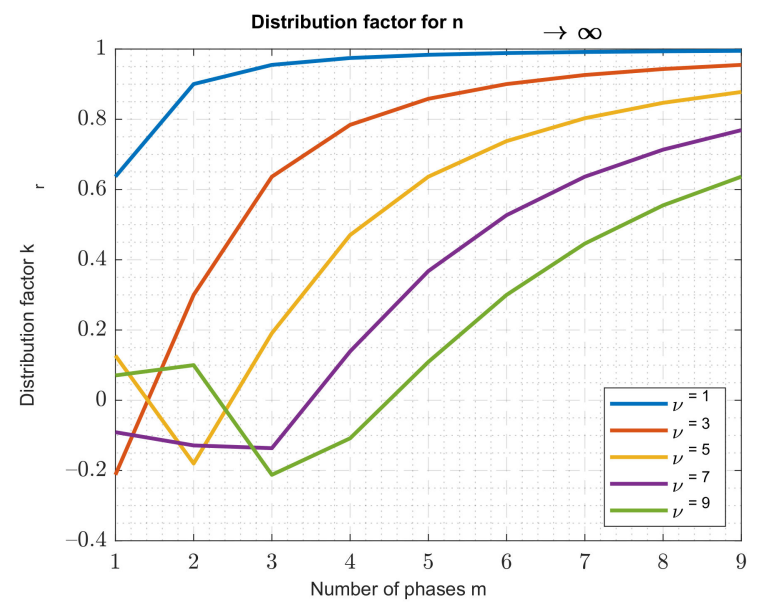

Figure 2. Distribution factor for different numbers of phases and spatial harmonics if $n \rightarrow \infty$.

The distribution factor of every spatial harmonic component increases with the number of phases. As described in [19], the stator copper loss of the induction machine is inversely proportional to the square of the winding factor. It was proven that the theoretical maximal reduction in stator copper loss is $8.8 \%$.

A real winding with a finite number of slots has a distribution factor according to (5). The number of slots of the electric machine is limited by the dimensions, technological limits, and by the manufacturing costs of the winding and connection of the coils. For example, in the case of three-phase traction induction motors, a relatively common number of slots per pole and phase is $q=4$. An identical stator design can be used for 6- and 12-phase winding while the number of slots per pole and phase is reduced to $q=2$ or $q=1$, respectively (also called "concentrated winding" in the literature $[4,19]$ ) with a winding distribution factor of $k_{r}=1$. The copper loss reduction is $7.9 \%$ in this case.

Furthermore, the coil pitch is being shortened to reduce the spatial harmonic content which is mathematically described by winding pitch factor $k_{y}$. The proportional coil pitch of three-phase windings is usually chosen to $\beta=5 / 6$ to maximize the reduction in the 5 th and 7th spatial harmonic components. This ideal value is commonly achieved by usage of 12 slots per pole and coil pitch equal to 10 slots.

The harmonic content of multiphase machines is naturally reduced by (9). The quality of produced magnetomotive force step curve can be quantized by the differential leakage factor, $\tau_{\text {diff, }}$ which is, in fact, the total harmonic distortion of the step curve:

$$
\tau_{\text {diff }}=\sum_{\substack{v=0 \\ v \neq 1}}^{\infty}\left(\frac{F_{m 1}}{F_{m v}}\right)^{2}=\sum_{\substack{v=0 \\ v \neq 1}}^{\infty}\left(\frac{k_{w 1}}{v k_{w v}}\right)^{2}
$$

The differential leakage factor of presented standard three-phase winding with $q=4$ with a coil pitch of $y_{1 s}=10$ is $0.64 \%$. An equivalent 12-phase winding with $q=1$ and a full coil pitch $\left(\beta=1, y_{1 s}=12\right)$ has a differential leakage factor of only $\tau_{\text {diff }}=0.57 \%$. The winding factor of fundamental harmonic component increases from 0.925 to 1 and the theoretical decrease in stator copper loss is $14.4 \%$, which is an even higher value than that presented in [19].

\subsection{Design of Fractional-Slot Windings}

The magnetomotive force step curve of fractional-slot winding is not fully symmetrical and it cannot be described by (8). The difference in the integer- and fractional-slot windings is graphically described by Figure $3 a, b$. These figures show the phase stars (respecting the electrical position of slots) with numbered coil sides of double-layer winding and phase belts created by front and back coil sides. 

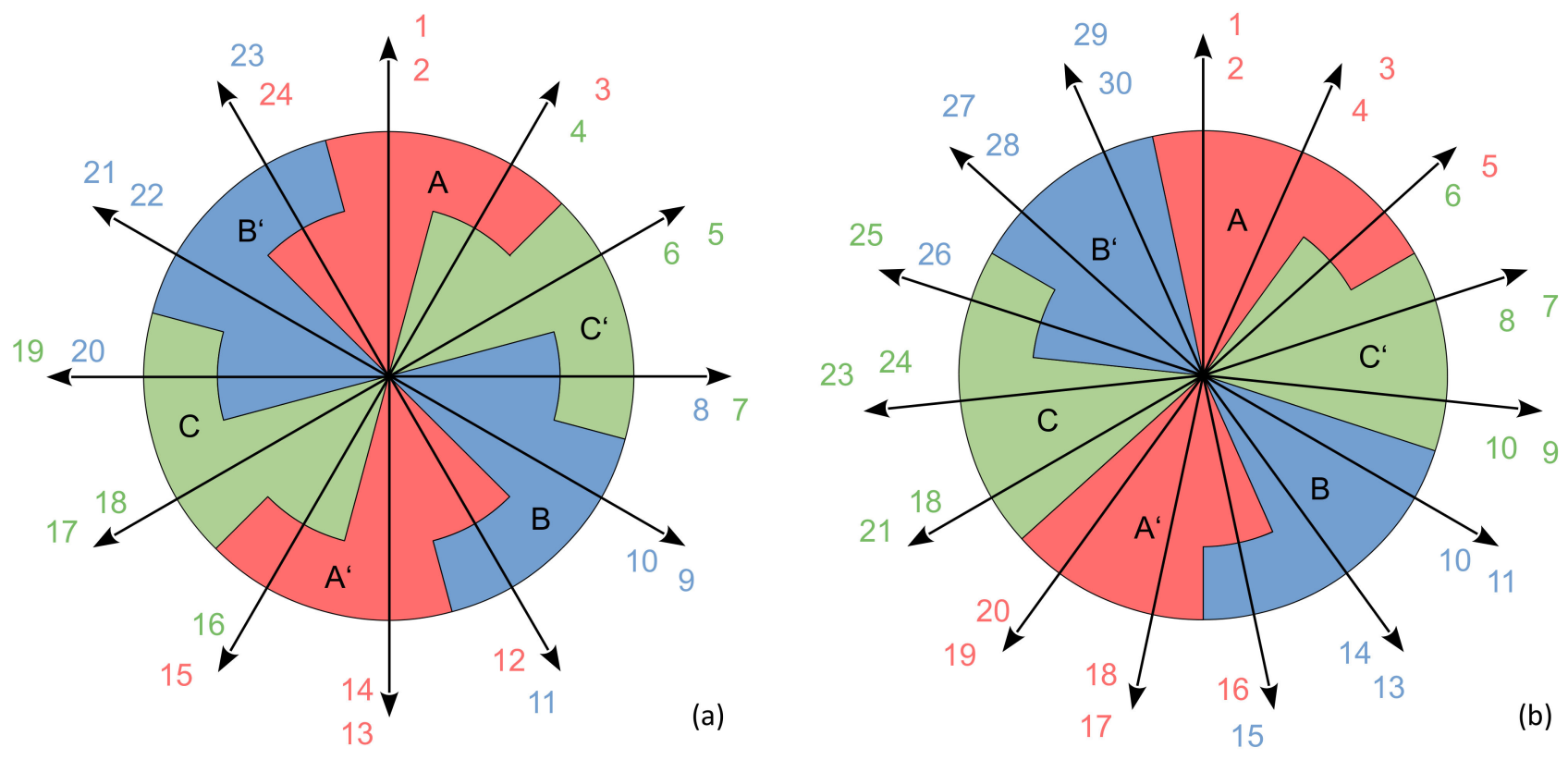

Figure 3. Star of slot phasors, numbered coil sides, and colored phase belts of three-phase winding with $q=2$ and winding step $y_{1 s}=5(\mathbf{a})$, and $q=5 / 2$ and winding step $y_{1 s}=7(\mathbf{b})$.

The final phase belts of all mathematical phases of the integer-slot winding are symmetrical and the winding is mathematically described by (8). The phase belts of fractional-slot windings are not fully symmetrical; the fractional-slot winding in Figure $3 b(c=2)$ has two types of phase belts distinguished for the physical phases $(\mathrm{A}, \mathrm{B}$, and $\mathrm{C})$ and mathematical phases $\left(\mathrm{A}^{\prime}, \mathrm{B}^{\prime}\right.$, and $\left.\mathrm{C}^{\prime}\right)$. The same effect can be observed with increasing $c$.

To define the mathematical description of the magnetomotive force produced by fractional-slot winding, it is necessary to decompose the winding to generally $2 p_{\min }$ independent symmetrical sub-windings with a mathematical number of phases, $m^{\prime}=m$, where $p_{\min }$ is the minimal required number of pole pairs of the machine, defined as:

$$
p_{\min }= \begin{cases}\frac{c}{2}, & \text { c even } \\ c, & \text { c odd }\end{cases}
$$

The geometrical axes of the phase belts of the same phase of different sub-windings are not parallel and the sub-windings are shifted by angle $\xi_{c}$, which generally differs from the multiples of $\pi$.

The number of slots per pole and phase of every sub-winding, $q^{\prime}$, is equal to the original number of slots per pole and phase, $q$, rounded up or down to ensure the average number of slots per pole and phase.

$$
\frac{1}{2 p_{\min }} \sum_{i=1}^{2 p_{\min }} q_{i}^{\prime}=q
$$

These sub-windings do not have mathematical phases $\left(m^{\prime}=m\right)$, and the final magnetomotive force (MMF) step curve can be described by a sum:

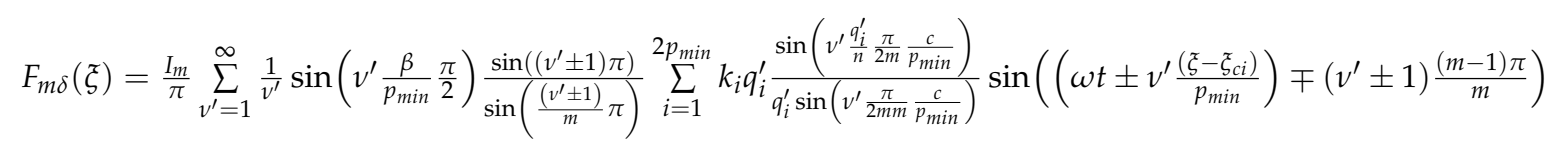

The winding can produce spatial sub-harmonic components; therefore, it is useful to define the spatial harmonic component $v^{\prime}=p_{\min } v$ to start the sum in (14) from the fundamental harmonic component for every type of winding. The coefficient $k_{i}$ defines the polarity of the current. 
The equation does not contain the distribution factor in the traditional form shown in (5), but the final distribution factor of the fractional-slot winding is defined by (5). In comparison to the integer-slot windings, the fractional-slot winding produces spatial harmonic components of order.

$$
v^{\prime}=k m \mp 1 \quad, \quad k=0,1,2, \ldots
$$

Winding with an Even Number of Phases

The presented rules of fractional-slot windings are of course also valid for windings with an even number of phases. Winding with $c=2$ has again two regularly alternating types of phase belts. However, when the winding has even number of phases, the chosen type of phase belt always belongs to one phase; the six-phase winding is then asymmetrical, as shown in Figure 4.

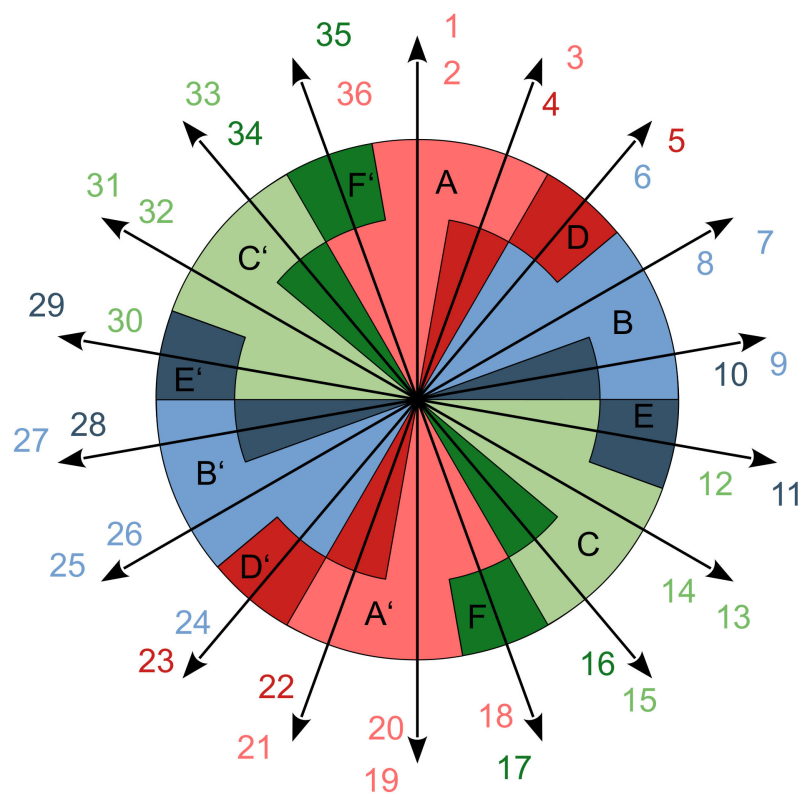

Figure 4. Star of slot phasors, numbered coil sides, and colored phase belts of six-phase winding with $q=3 / 2$ and winding step $y_{1 s}=8$.

It is obvious that the winding splits into two symmetrical three-phase windings, where each of them has a different number of slots per pole and phase and winding factor. It can be generalized that the asymmetrical $m$-phase winding with an even number of phases and an even denominator of the number of slots per pole and phase $c$ separate to two symmetrical windings with $m / 2$ phases.

This effect has been discussed in the literature [20-23]; the work in this area is mainly focused on the dual power supply of two sets of the winding and the symmetrization of the currents. If this is not a desired effect, the designer of the magnetic circuit and the winding should avoid the fractional-slot winding with an even denominator, $c$.

\subsection{Higher Order Harmonic Components Injection}

As described in [4], the harmonic components injection is usually possible for every concentrated multiphase winding with an odd number of phases. The condition for using higher order time harmonic components injection is that they must create an electromagnetic field that rotates with the same speed as the field generated by the fundamental harmonic component. In the case of concentrated winding this condition is met for every odd time harmonic whose order is less than the number of phases. These harmonics create a $\mu$-times higher number of pole pairs than the fundamental harmonic component, and it 
is possible to use them for flattening the voltage, magnetic flux, or current waveform to achieve higher torque density without an undesirable increase in noise or vibrations.

The magnetomotive force of the integral-slot winding (8), excited by the $\mu$-th harmonic component, is modified to:

$$
F_{m \delta}^{\mu}(\xi)=\frac{q I_{m}^{\mu}}{\pi} \sum_{v=1}^{\infty} \frac{1}{v} \sin \left(v \beta \frac{\pi}{2}\right) \frac{\sin \left(v \frac{\pi}{2 m}\right)}{n \sin \left(v \frac{\pi}{2 m n}\right)} \frac{\sin ((v \pm \mu) \pi)}{\sin \left(\frac{(v \pm \mu)}{m \prime} \pi\right)} \sin \left((\omega t \pm v \xi) \mp(v \pm \mu) \frac{\left(m^{\prime}-1\right)}{m^{\prime}} \pi\right)
$$

fractional-slot windings.

$$
F_{m \delta}^{\mu}(\xi)=\frac{I_{m}^{\mu}}{\pi} \sum_{v^{\prime}=1}^{\infty} \frac{1}{v^{\prime}} \sin \left(v^{\prime} \frac{\beta}{p_{\text {min }}} \frac{\pi}{2}\right) \frac{\sin \left(\left(v^{\prime} \pm \mu\right) \pi\right)}{\sin \left(\frac{\left.v^{\prime} \pm \mu\right)}{m} \pi\right)} \sum_{i=1}^{2 p_{\min }} k_{i} q_{i}^{\prime} \frac{\sin \left(v^{\prime} \frac{q_{i}^{\prime}}{n} \frac{\pi}{2 m} \frac{c}{p_{\min }}\right)}{q_{i}^{\prime} \sin \left(v^{\prime} \frac{\pi}{2 m m} \frac{c}{p_{\text {min }}}\right)} \sin \left(\left(\mu \omega t \pm v^{\prime} \frac{\left(\tilde{s}-\xi_{c i}\right)}{p_{\min }}\right) \mp\left(v^{\prime} \pm \mu\right) \frac{(m-1) \pi}{m}\right)
$$

The non-zero produced spatial harmonic components have orders of

$$
\left\{\begin{array}{l}
v=k m^{\prime} \mp \mu \quad \text { integral - slot winding } \\
v^{\prime}=k m \mp \mu \quad \text { fractional - slot winding }
\end{array} \quad, k=0,1,2, \ldots\right.
$$

Applying the higher order harmonic component injection to the machine, the final magnetomotive step curve is calculated as a sum of (16) or (17) for all applied time harmonics. The higher harmonic component will have different amplitudes, $I_{m \mu}$, and they can have a generally different phase shift.

The magnetomotive force step curve produced by the winding under the injection of higher time harmonic components can or cannot be symmetrical, independent of the symmetry of the step curve produced by the first harmonic component. For example, a nine-phase machine with $q=1$ under the third time harmonic component injection creates, according to [5], three-fold more poles, and the virtual number of slots per pole and phase is now $q_{v}=1 / 3$. Nevertheless, the produced magnetomotive force step curve is symmetrical. Compared to that, the five-phase machine with $q=3$ under the third time harmonic injection has a virtual number of slots per pole and phase of $q_{v}=1$, but the produced magnetomotive force step curve is asymmetrical. Comparison of both magnetomotive force step curves is shown in Figure 5.
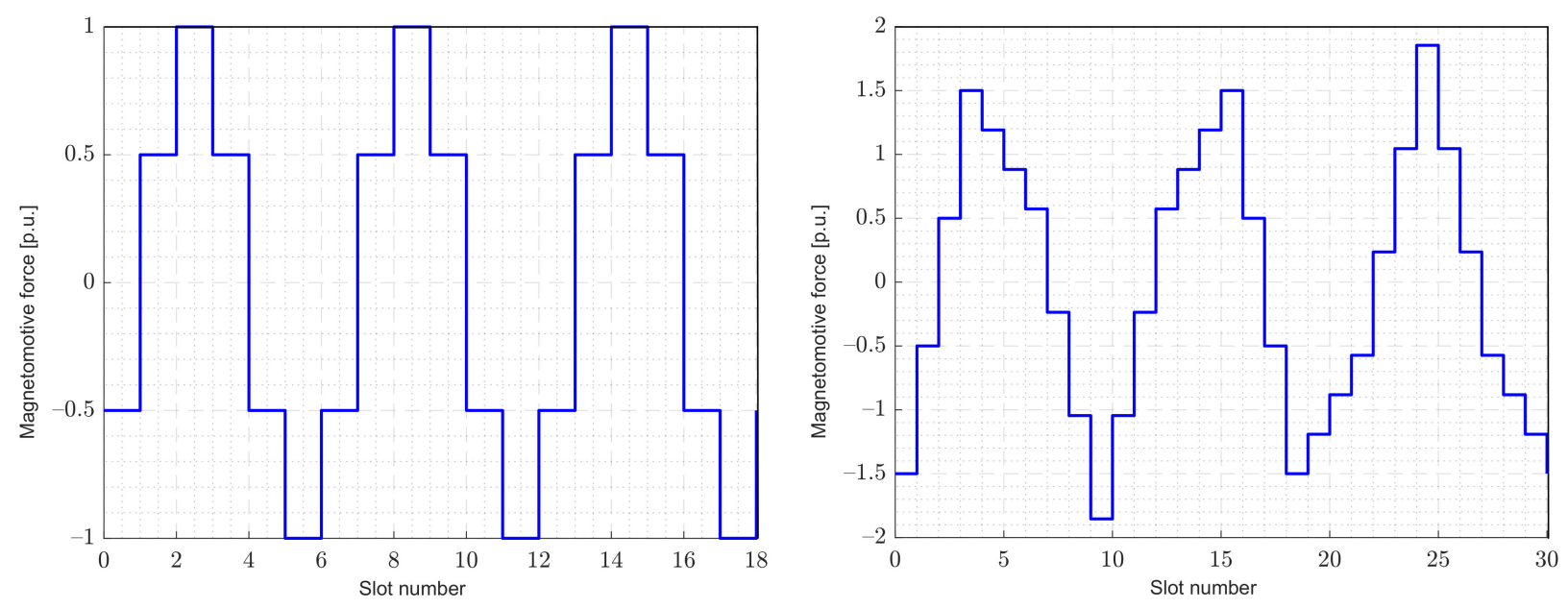

Figure 5. Magnetomotive force step-curve produced by injection of the third harmonic time component into the nine-phase winding with $q=1$ and into the five-phase winding with $q=3$.

It can be generalized that if the number of phases is a multiple of the injected time harmonic component, some phasors respecting the phase currents or voltages will have the same phase shift and create $m / \mu$ identical windings with a symmetrical MMF step 
curve. If this condition is not met, the produced MMF step curve is asymmetrical and can produce additional torque pulsations in the induction machines.

The injection of higher harmonics into the terminal voltage causes different phase shifts of different harmonic components of the current of the loaded machine and it can be difficult to estimate its waveform. Under the no-load operation, the zero-phase shift of the sinusoidal time harmonic waveforms can be assumed.

The other possibility is to directly control the current waveform, which is mostly used in synchronous machines. It was proven in [24] that the biggest torque increase in permanent magnet synchronous machines is achieved if the sinusoidal currents of the fundamental and third harmonic are not phase-shifted and the current waveform is symmetrically flattened. This effect is mainly caused by the flattened distribution of the magnetic flux density excited by the permanent magnet rotors.

For both discussed cases, the stator current waveform can be approximately described by a sum:

$$
i(\omega t)=\sum_{\mu=1,3,5, \ldots} I_{m}^{\mu} \sin \mu \omega t
$$

The polarity of the higher order harmonic components can be generally different and depends on the analyzed state.

\section{Calculation of Equivalent Circuit Parameters}

Although the equations for the equivalent circuit parameters calculation are defined universally for $m$-phases a detailed analysis, especially of the calculation of inductance, can bring different results. The magnetic field in the air gap produced by the winding is quantified by the armature reaction (or magnetizing, main) inductance, $L_{a}$, produced by the fundamental harmonic component and the differential leakage inductance, $L_{\text {diff. }}$. Both inductances are defined in the literature [25-28] as:

$$
\begin{gathered}
L_{a}=\mu_{0} \alpha_{\delta} m \frac{t_{p}}{\pi p\left(\delta^{\prime \prime}+\frac{h_{m}}{\mu_{r m}}\right)} l_{F e}\left(N_{s} k_{w}\right)^{2}, \\
L_{\text {diff }}=\tau_{\text {diff }} L_{a}
\end{gathered}
$$

where $\alpha_{\delta}$ is the pole cover ratio and $\delta^{\prime \prime}$ is the equivalent air gap length, respecting the slotting and the saturation of the magnetic circuit; for the surface-mounted permanent magnet machine, the magnetic air gap is increased by the PM height and divided by its relative permeability, $h_{m} / \mu_{r m}$.

Injecting the suitable higher order time harmonic components, $\mu$, will increase the number of poles $\mu$-times, which $\mu$-times decreases the pole pitch; the armature reaction inductance $L_{a}{ }^{\mu}$ is then:

$$
L_{a}^{\mu}=\mu_{0} \alpha_{\delta} m \frac{t_{p}}{\pi p\left(\delta^{\prime \prime}+\frac{h_{m}}{\mu_{r m}}\right)} l_{F e}\left(N_{s} \frac{k_{w \mu}}{\mu}\right)^{2},
$$

The winding factor of the fundamental harmonic component produced by the higher harmonic is calculated by the substitution $v=\mu$ in (4)-(6).

The combination of the harmonic components modifies the distribution of the flux density in the air gap and affects the armature reaction inductance and the differential leakage inductance. The inductance of each time component represents the magnetic field excited by the harmonic current component with the amplitude $I_{m}{ }^{\mu}$; the main inductance excited by all harmonic component is then defined as a sum:

$$
L_{a}=\mu_{0} \alpha_{\delta} m \frac{t_{p}}{\pi p\left(\delta^{\prime \prime}+\frac{h_{m}}{\mu_{r m}}\right)} l_{F e} N_{s}^{2} \sum_{\mu}\left(\frac{k_{w \mu}}{\mu}\right)^{2},
$$




\subsection{Slot Leakage Inductance}

The slot leakage inductance of one phase is calculated (see [25-28]) as:

$$
L_{\sigma s}=2 \mu_{0} \frac{\lambda_{s}}{p q} l_{F e} N_{s}^{2},
$$

where the number of phases is included in $q$. The slot permeance coefficient $\lambda_{s}$ is mainly defined by the slot shape and its dimensions, and also by the number of winding layers and winding step. For the double-layer winding, the slot permeance coefficient is generally defined in the literature [25-28] as:

$$
\lambda_{s}=k_{C u} \lambda_{C u}+k_{k e} \lambda_{k e},
$$

where $\lambda_{C u}$ and $\lambda_{k e}$ are the slot permeance factors of the active slot area (winding slot area) and the area of the slot wedge and slot opening, respectively, defined in [25-28] and modified in [29]. The coefficients $k_{C u}$ and $k_{k e}$ respect the effect of the coil pitch shortening, and the most common formulas for both coefficients are:

$$
\begin{gathered}
k_{k e}=0.25(1+3 \beta) \\
k_{C u}=\frac{7}{16}+\frac{9}{16} \beta=0.25\left(1+3 k_{k e}\right)
\end{gathered}
$$

These coefficients are only valid for three-phase windings with a relative coil pitch in the range of $\beta \in\langle 2 / 3 \beta ; 4 / 3 \beta\rangle$.

To generalize the coefficients $k_{k e}$ and $k_{C u}$, it is suitable to define a general coefficient, $k_{\lambda}$, as a ratio of the inductance of a short-pitched winding to a full-pitched winding by the ratio of the number of slots fully and partially filled by the coil sides belonging to one phase. For a three-phase winding, the coefficient $k_{\lambda}$ for the relative coil pitch in the range of $\beta \in\langle 2 / 3 ; 4 / 3\rangle$ is derived as:

$$
\begin{gathered}
k_{\lambda}=\frac{t_{p d}\left(\beta-\frac{2}{3}\right) \lambda_{f}+t_{p d}(1-\beta) \lambda_{p}}{\frac{1}{3} t_{p d} \lambda_{f}}=\frac{(3 \beta-2) \lambda_{f}+3(1-\beta) \lambda_{p}}{\lambda_{f}}= \\
=3 \beta-2+3(1-\beta) \frac{\lambda_{p}}{\lambda_{f}}
\end{gathered}
$$

where $\lambda_{f}$ is generally the slot permeance factor of the slot filled by coil sides belonging to the same phase and $\lambda_{p}$ is the sum of slot permeance factors of a pair of slots with one coil side belonging to the same phase.

In the case of three-phase windings with horizontally divided winding layers, the coefficients are shown in (26). In cases where the winding layers are divided vertically (typically for the tooth winding), it can be proven that the ratio of $\lambda_{p} / \lambda_{f}(27)$ is identical and $k_{\mathrm{C} u}=k_{k e}$; this equality is valid for all numbers of phases and all coil pitch ratios.

In the case of three-phase windings, all practically used windings have a relative coil pitch in the range of $\beta \in\langle 2 / 3 ; 4 / 3\rangle$. With an increasing number of phases, the limiting values of these ratios (defined by shifting of the back coil sides under front coil sides belonging to different phases) are changing; the boundaries for an $m$-phase winding are defined as:

$$
\beta \epsilon\left(1-k \frac{1}{m} ; 1-(k-1) \frac{1}{m}\right) \cup\left(1+(k-1) \frac{1}{m} ; 1+k \frac{1}{m}\right), k=1,2, \ldots, m
$$

It can be derived that for every $k$, the coefficients $\lambda_{p}{ }^{(k-1)}$ and $\lambda_{p}{ }^{(k)}$ are applied in the number of $t_{p d}\left(\beta-\frac{m-k}{m}\right)$ and $t_{p d}\left(\frac{m-(k-1)}{m}-\beta\right)$. The generalized ratio $k_{\lambda}$ is then: 


$$
\begin{gathered}
k_{\lambda}=\frac{t_{p d}\left(\beta-\frac{m-k}{m}\right) \lambda_{p}^{(k-1)}+t_{p d}\left(\frac{m-(k-1)}{m}-\beta\right) \lambda_{p}^{(k)}}{\frac{1}{m} t_{p d} \lambda_{f}}= \\
=(\beta m-m+k) \frac{\lambda_{p}^{(k-1)}}{\lambda_{f}}+(m-k+1-\beta m) \frac{\lambda_{p}^{(k)}}{\lambda_{f}}
\end{gathered}
$$

For the slot opening and slot wedge area, the ratio $\lambda_{p}{ }^{(k)} / \lambda_{f}$ is derived by the calculation of the self- and mutual component of the inductance described in [30] as:

$$
\frac{\lambda_{p}^{(k)}}{\lambda_{f}}=\frac{1+\cos \left(\alpha_{k}\right)}{2},
$$

and for the winding area of a horizontally divided slot:

$$
\frac{\lambda_{p}^{(k)}}{\lambda_{f}}=\frac{5+3 \cos \left(\alpha_{k}\right)}{8},
$$

where $\alpha_{k}$ is the phase shift of the sinusoidal current of the analyzed phase and the next $k$-th phase of the winding with a mathematical number of phase $m^{\prime}=2 m$ :

$$
\alpha_{k}=\frac{(k-1) \pi}{m}
$$

For the slot opening and slot wedge area, the $k_{k e}$ coefficient equals by the substitution of (30) to (29):

$$
\begin{aligned}
& k_{k e}^{(m, k)}=(\beta m-m+k) \frac{1+\cos \left(\frac{(k-1) \pi}{m}\right)}{2}+(m-k+1-\beta m) \frac{1+\cos \left(\frac{k \pi}{m}\right)}{2}= \\
& =\frac{1}{2}+\frac{1}{2}\left[(\beta m-m+k) \cos \left(\frac{(k-1) \pi}{m}\right)+(1-k+m-\beta m) \cos \left(\frac{k \pi}{m}\right)\right]
\end{aligned}
$$

and for the winding are by the substitution of (31) to (29):

$$
\begin{gathered}
k_{C u}^{(m, k)}=(\beta m-m+k) \frac{5+3 \cos \left(\frac{(k-1) \pi}{m}\right)}{8}+(m-k+1-\beta m) \frac{5+3 \cos \left(\frac{k \pi}{m}\right)}{8}= \\
=\frac{5}{8}+\frac{3}{8}\left[(\beta m-m+k) \cos \left(\frac{(k-1) \pi}{m}\right)+(1-k+m-\beta m) \cos \left(\frac{k \pi}{m}\right)\right]
\end{gathered}
$$

The expression in brackets in (33) and (34) can be, according to [31,32], substituted by correction factor $k_{c}^{(m, k)}$, and coefficients $k_{k e}$ and $k_{\mathrm{Cu}}$ are equal to:

$$
\begin{aligned}
& k_{k e}^{(m, k)}=\frac{1+k_{c}^{(m, k)}}{2} \\
& k_{C u}^{(m, k)}=\frac{5+3 k_{c}^{(m, k)}}{8}
\end{aligned}
$$

By increasing the number of phases to infinity, $m \rightarrow \infty$, the coefficient $k$ is changed continuously according to:

$$
k_{(m \rightarrow \infty)}=(1-\beta) m+1
$$

By the substitution of (36) into $k_{c}{ }^{(m, k)}$ expression, the coefficient can be derived as:

$$
\begin{gathered}
k_{c}^{(m \rightarrow \infty)}=(\beta m-m+(1-\beta) m+1) \cos \left(\frac{((1-\beta) m+1-1) \pi}{m}\right)+ \\
+(1-(1-\beta) m+1+m-\beta m) \cos \left(\frac{((1-\beta) m+1) \pi}{m}\right)= \\
=\cos (1-\beta) \pi=-\cos \beta \pi,
\end{gathered}
$$


which is used in graphical form in [32]. It can be proven that, for every number of phases, the correction factor $k_{c}$ is equal to (37) for every relative coil pitch defined by (28). Between these points, the linear interpolation can be used to obtain the value of coefficient $k_{c}{ }_{c}^{(m, k)}$. According to [32], the maximal relative deviation of the real interpolated function from the idealized cosine function is smaller than $1.5 \%$ for the nine-phase winding. Thus, the accuracy is sufficient and (37) can be used for winding with nine and more phases.

In [32] the values of the correction factors $k_{c}$ are derived for different numbers of phases (five, six, and seven) and a relative coil pitch is assigned to coefficient $k$ by (28). These results are summarized in Table VI in [32]. The authors of this paper wish to point out an error in the case of seven-phase winding in this table, and therefore we are presenting the corrected values, including the reference three-phase winding in Table 2. If the reader wishes to derive the correction factor for a different number of phases or a different relative coil pitch, the coefficient $k$ has to be found according to (28), and $k_{c}, k_{k e}$, and $k_{C u}$ are calculated according to (33)-(35).

Table 2. Summarized correction factor $k_{c}$ for different numbers of phases and coefficient $k$.

\begin{tabular}{cccc}
\hline $\begin{array}{c}\text { Number of } \\
\text { Phases, } \boldsymbol{m}\end{array}$ & $\boldsymbol{k}$ & Relative Coil Pitch, $\boldsymbol{\beta}$ & Correction Factor, $\boldsymbol{k}_{\boldsymbol{c}}$ \\
\hline 3 & 1 & $\left\langle\frac{2}{3} ; \frac{4}{3}\right\rangle$ & $0.5(3 \beta-1)$ \\
5 & 1 & $\left\langle\frac{4}{5} ; \frac{6}{5}\right\rangle$ & $0.955 \beta+0.045$ \\
& 2 & $\left\langle\frac{3}{5} ; \frac{4}{5}\right\rangle \cup\left\langle\frac{6}{5} ; \frac{7}{5}\right\rangle$ & $2.5 \beta-1.191$ \\
6 & 1 & $\left\langle\frac{5}{6} ; \frac{7}{6}\right\rangle$ & $(6-3 \sqrt{3}) \beta+3 \sqrt{3}-5$ \\
& 2 & $\left\langle\frac{4}{6} ; \frac{5}{6}\right\rangle \cup\left\langle\frac{7}{6} ; \frac{8}{6}\right\rangle$ & $(3 \sqrt{3}-3) \beta+2.5-2 \sqrt{3}$ \\
7 & 1 & $\left\langle\frac{6}{7} ; \frac{8}{7}\right\rangle$ & $0.693 \beta+0.307$ \\
& 2 & $\left\langle\frac{5}{7} ; \frac{6}{7}\right\rangle \cup\left\langle\frac{8}{7} ; \frac{9}{7}\right\rangle$ & $1.942 \beta-0.764$ \\
Nine and more & 3 & $\left\langle\frac{4}{7} ; \frac{5}{7}\right\rangle \cup\left\langle\frac{9}{7} ; \frac{10}{7}\right\rangle$ & $2.807 \beta-1.381$ \\
\hline
\end{tabular}

Higher Order Harmonic Component Injection

Applying a single higher order harmonic current component, $\mu$, similarly to armature reaction inductance, $\mu$-times increases the number of poles, and the number of slots per pole and phase therefore decreases by $\mu$-times. Equation (24) is then modified to:

$$
L_{\sigma s}^{\mu}=2 \mu_{0} \frac{\lambda_{s}}{p q} l_{F e}\left(\frac{N_{s}}{\mu}\right)^{2}
$$

The conditions of the higher harmonic injection are summarized in [5] and the stator current waveform is described by (19). The reference phase position of the analyzed winding is given by the amplitude of the fundamental harmonic $\omega t=\pi / 2$. The phase shift of the next $k$-th phase belt is still defined by (32) and at a chosen time point is the current of every phase belt defined as:

$$
i_{k}=\sum_{\mu=1,3,5, \ldots} I_{\mu} \sin \mu\left(\frac{\pi}{2}+\frac{k \pi}{m}\right) .
$$

The ratios (30) and (31) can be generalized to:

$$
\frac{\lambda_{p}^{(k)}}{\lambda_{f}}=\frac{1+i_{k}}{2}
$$




$$
\frac{\lambda_{p}^{(k)}}{\lambda_{f}}=\frac{5+3 i_{k}}{8},
$$

Applying the same procedure as in (33)-(37), the correction factor equals:

$$
k_{c}^{(m, k)}=(\beta m-m+k) i_{k-1}+(1-k+m-\beta m) i_{k}
$$

and the theoretical convergence value for $m \rightarrow \infty$ is:

$$
k_{c}^{(m \rightarrow \infty)}=\sum_{\mu=1,3,5, \ldots} I_{\mu} \sin \mu\left(\frac{3}{2}-\beta\right) \pi .
$$

This calculation is based on the assumption that the current waveform has its maximum at a position $\omega t=\pi / 2$. It is necessary to note that this assumption is generally not always met. In the case of the injection of odd-order harmonic components, a local minimum is located at this time point; thus, the derived approach is not valid for similar cases.

A seven-phase winding with injected third and fifth harmonic components is chosen as an example; the optimized ratio of every harmonic is derived in [33] and it is used in this paper. The graphical interpretation of the results is shown in Figures 6 and 7.
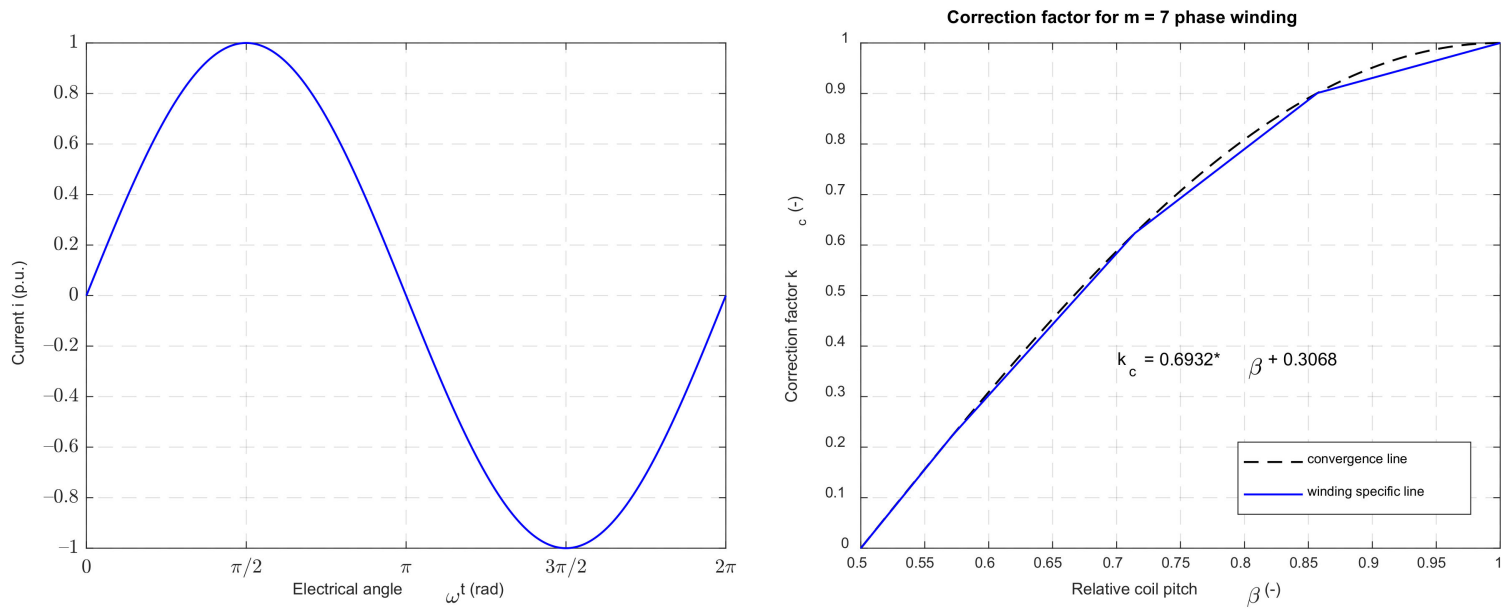

Figure 6. Waveform of harmonic current and the correction factor, $\mathrm{k}_{\mathrm{c}}$, of seven-phase winding.
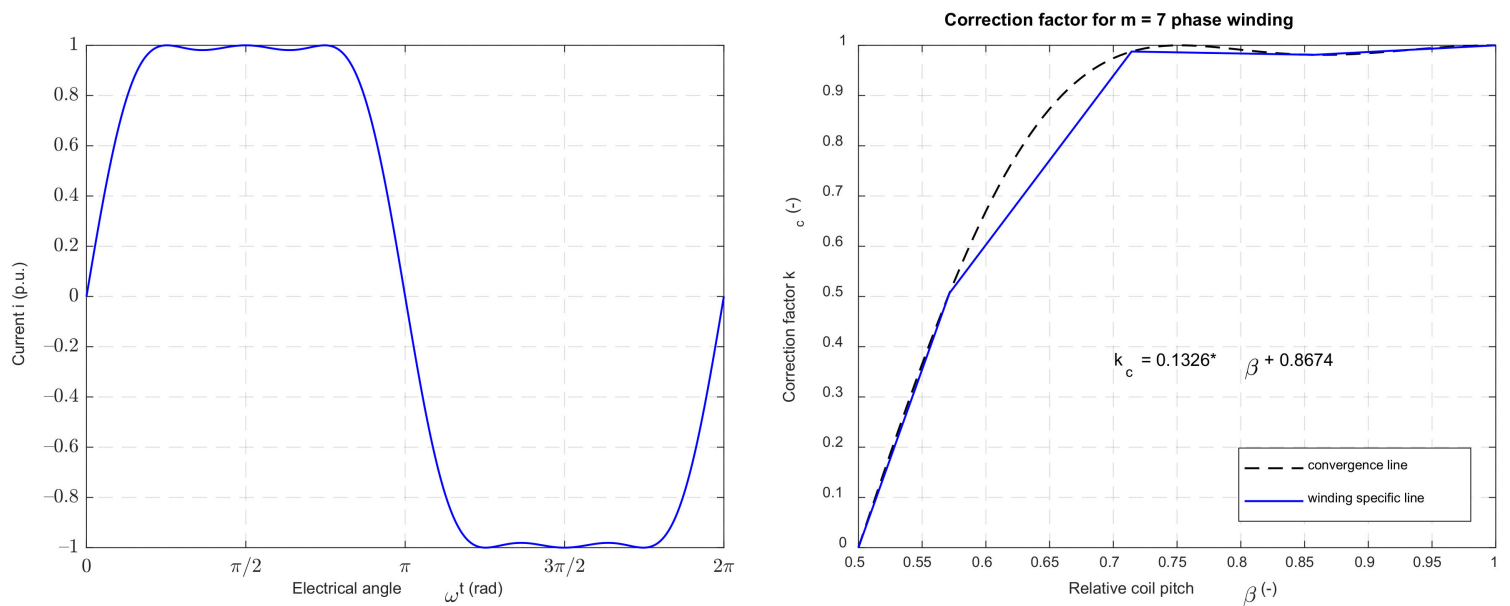

Figure 7. Waveform of current with injected third and fifth harmonic components and the correction factor, $\mathrm{k}_{\mathrm{c}}$, of sevenphase winding. 
The convergence line of the correction factor, $\mathrm{k}_{\mathrm{c}}$, is directly defined by the current waveform and it is possible to apply this approach for the opposite polarity of the higher harmonic component caused by the flattened voltage waveform.

\section{Example of a Nine-Phase Induction Machine}

An example of the calculation is shown in the case of the nine-phase induction machine also presented in [33]. The main parameters of the motor are summarized in Table 3 and the measuring stand of the motor is shown in Figure 8a.

Table 3. Motor parameters.

\begin{tabular}{cc}
\hline Parameter & Value \\
\hline Number of pole pairs & 2 \\
Number of phases & 9 \\
Rated power (kW) & 15 \\
Rated phase voltage (V) & 380 \\
Rated current (A) & 5.85 \\
Rated power factor (-) & 0.82 \\
Rated efficiency (-) & 0.91 \\
Rated frequency (Hz) & 50 \\
Rated speed & 1480 \\
Number of stator slots & 36 \\
\hline
\end{tabular}

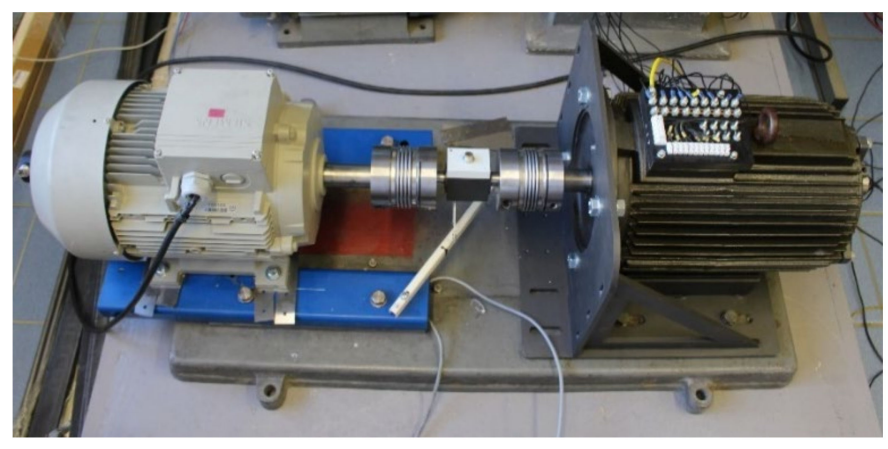

(a)

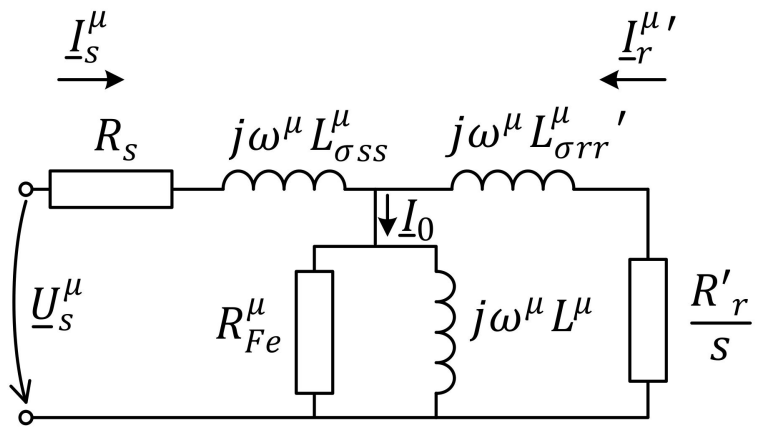

(b)

Figure 8. Measuring stand of a nine-phase induction machine and (a) the equivalent circuit, respecting different time harmonic components (b).

The machine was measured in the no-load state at a reduced voltage/frequency ratio of $U / f=7.7 \mathrm{~V} / \mathrm{Hz}$ to avoid oversaturation of the magnetic circuit. Under these conditions, the magnetic circuit can be presumed to have a linear characteristic and the superposition of inductances can be applied and evaluated. The motor has a single-layer winding and a correction factor of $k_{r}=1$, so the injection of higher harmonics influences the slot inductance according to (38), where $\lambda_{S}$ is constant. The calculated stator inductances are summarized in Table 4, respecting the equivalent circuit in Figure 8b.

Under the no-load operation, the current is limited by the stator reactance and resistance, $R_{s}$. The resistance/inductance ratio increases with an increasing time harmonic, and therefore the ideal phase shift of $90^{\circ}$ cannot be achieved. The measured ratio of voltage harmonic components is used for both analytical and finite element method (FEM) calculation, and the currents are compared in Table 5. 
Table 4. Parameters of the machine under different time harmonic excitation.

\begin{tabular}{cccc}
\hline & \multicolumn{3}{c}{ Time Harmonic Component Order, $\boldsymbol{\mu}(-)$} \\
\cline { 2 - 4 } & $\mathbf{1}$ & $\mathbf{3}$ & $\mathbf{5}$ \\
\hline Angular frequency, $\omega\left(\mathrm{rad} \cdot \mathrm{s}^{-1}\right)$ & 75.4 & 226.2 & 377.0 \\
Main inductance, $L(\mathrm{H})$ & 0.598 & 0.0664 & 0.0239 \\
Differential leakage factor, $\tau_{\text {diff }}(\%)$ & 1.02 & 9.66 & 29.8 \\
Differential leakage inductance, $L_{\text {diff }}(\mathrm{H})$ & 0.00611 & 0.00632 & 0.00712 \\
Slot leakage inductance, $L_{\sigma s}(\mathrm{H})$ & 0.00568 & $6.31 \cdot 10^{-4}$ & $2.27 \cdot 10^{-4}$ \\
Total stator inductance, $L_{S}(\mathrm{H})$ & 0.610 & 0.0735 & 0.0313 \\
Stator reactance, $X_{S}(\Omega)$ & 45.98 & 16.62 & 11.79 \\
\hline
\end{tabular}

Table 5. Harmonic component currents: comparison among the results of analytical calculation, finite element method analysis (FEA), and measurement.

\begin{tabular}{|c|c|c|c|c|}
\hline \multirow[b]{2}{*}{ Time harmonic component order $\mu(-)$} & \multirow{2}{*}{$\begin{array}{c}\begin{array}{c}\text { Single } \\
\text { Harmonic }\end{array} \\
1\end{array}$} & \multicolumn{3}{|c|}{ Higher Order Harmonic Injection } \\
\hline & & 1 & 3 & 5 \\
\hline Time harmonic component, $\mu(-)$ & 1 & 1 & 3 & 5 \\
\hline Voltage, $U_{m}(\mathrm{~V})$ & 92.5 & 111.8 & 25.6 & 6.28 \\
\hline Stator reactance, $X_{S}(\Omega)$ & 45.98 & 45.98 & 16.62 & 11.79 \\
\hline Stator resistance, $R_{S}(\Omega)$ & \multicolumn{4}{|c|}{1.36} \\
\hline Stator impedance, $Z_{S}(\Omega)$ & 46.00 & 46.00 & 16.68 & 11.87 \\
\hline Phase shift, $\varphi\left(^{\circ}\right)$ & 88.3 & 88.3 & 85.3 & 83.4 \\
\hline Analytical & 2.01 & 2.43 & 1.54 & 0.53 \\
\hline Current, $I(\mathrm{~A})$ & 2.14 & 2.63 & 1.44 & 0.46 \\
\hline Measurement & 2.12 & 2.63 & 1.473 & 0.45 \\
\hline
\end{tabular}

The terminal voltage waveforms are compared in Figure 9 and the resulting current waveforms are shown in Figure 10.
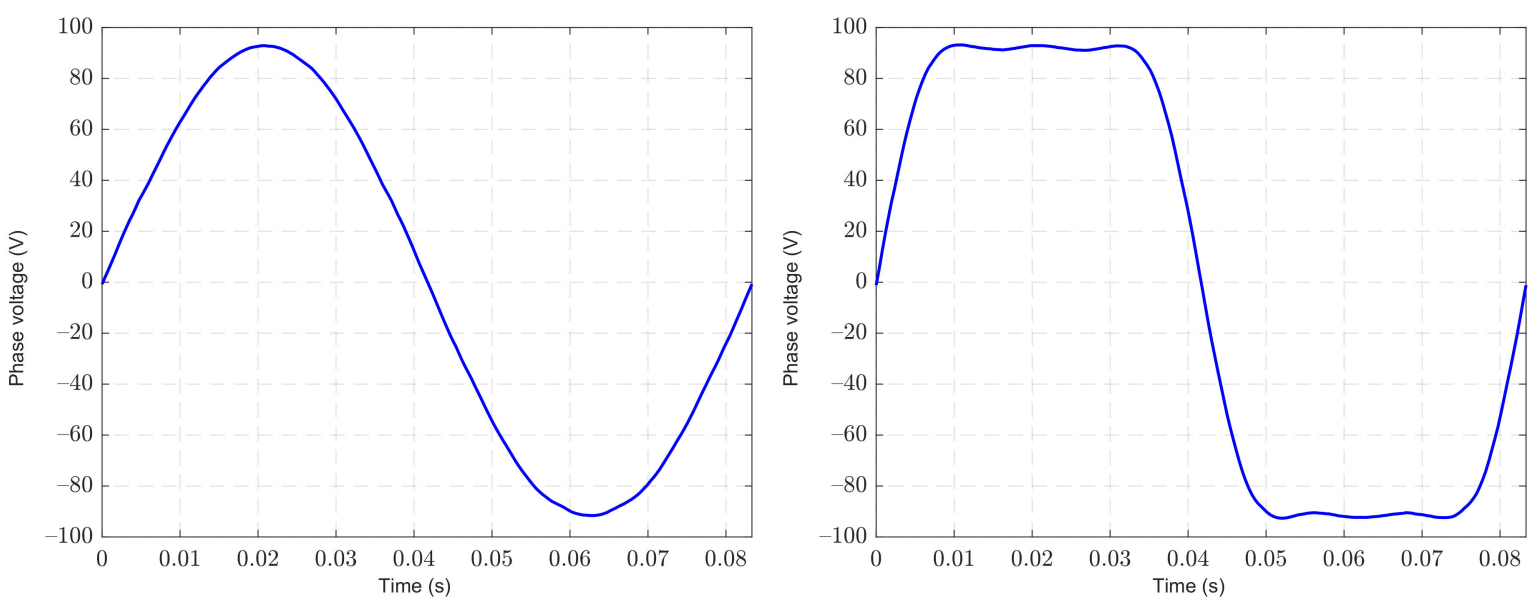

Figure 9. Voltage waveforms of single and higher order harmonic components injection. 

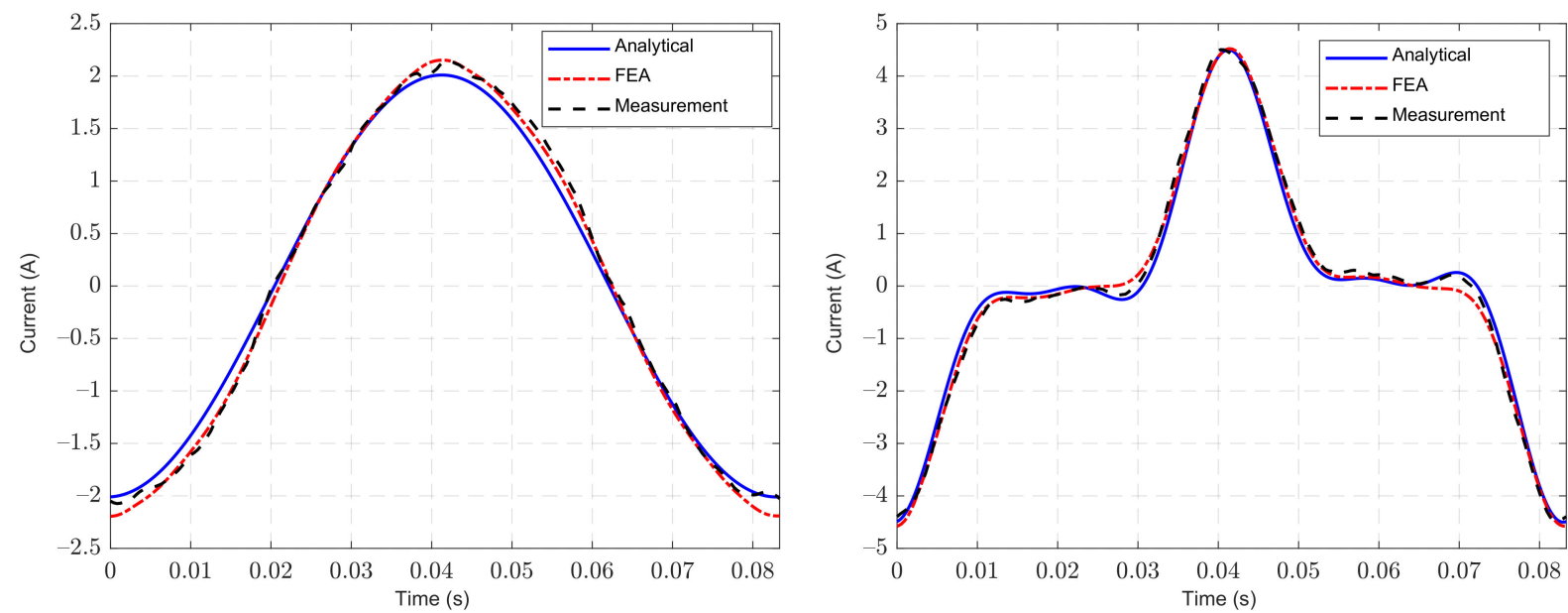

Figure 10. Current waveforms of single and higher order harmonic components injection obtained by analytical calculation, FEA, and measurement.

The calculated values of inductances are verified by the no-load current response, and the air gap inductances can be also verified by the comparison of distribution of the air gap flux density. The analytical calculation is based on (8); the machine has an additional testing coil wound on one stator tooth. Based on the measured voltage induced in this coil and calculated flux linkage waveform, the air gap flux density distribution is calculated. The obtained results for both single harmonic and higher order harmonic injection are summarized in Figure 11.
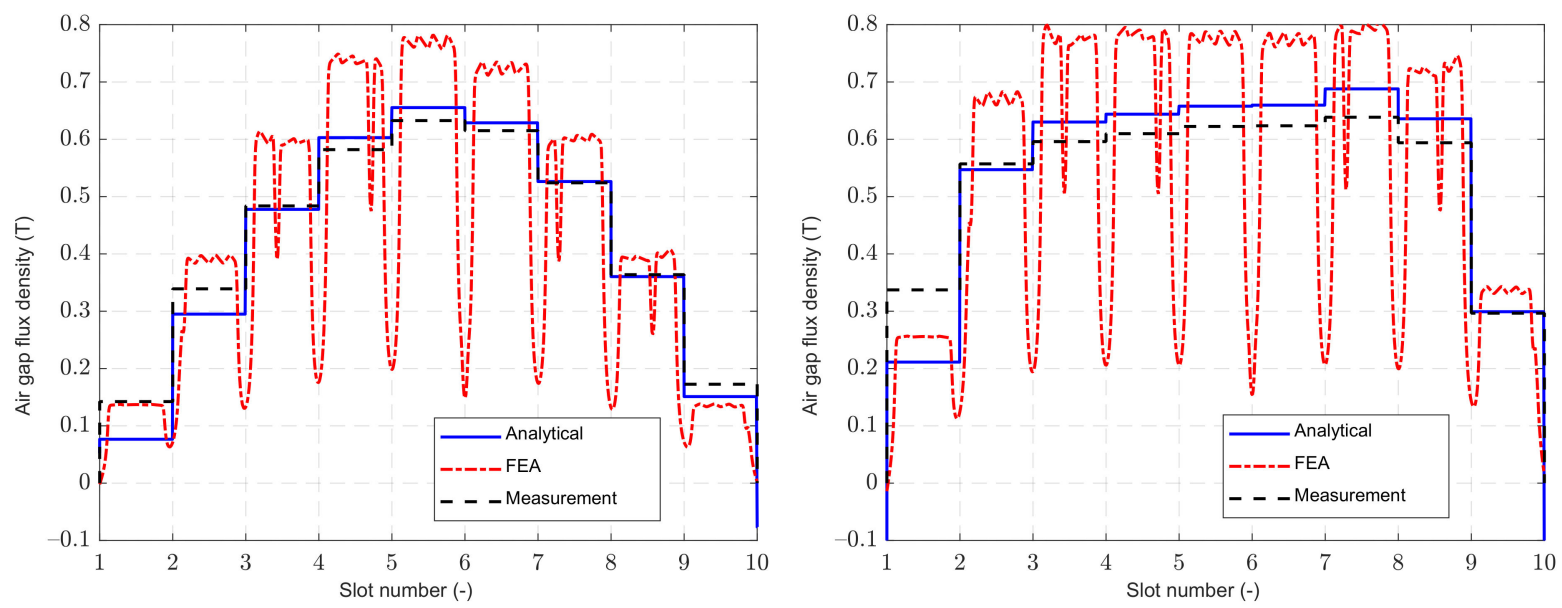

Figure 11. Air gap magnetic flux density excited by single and higher order harmonic components injection obtained by analytical calculation, FEA, and measurement.

The results calculated by the finite element analysis include the effect of slot opening of both stator and rotor slots, while this effect is in the analytical calculation only respected by the Carter's coefficient [25] and cannot be recorded by the measurement of the flux linked with a single stator tooth; therefore, the fast Fourier transform is applied to the waveforms to compare the contribution of the harmonic components to the final flux density distribution. Based on the Figure 12, it is obvious that the measured air gap flux density includes higher harmonic components with a higher amplitude in comparison with the analytical and finite element calculations; it can be caused by the rotor currents in the no-load state of the induction motor. 

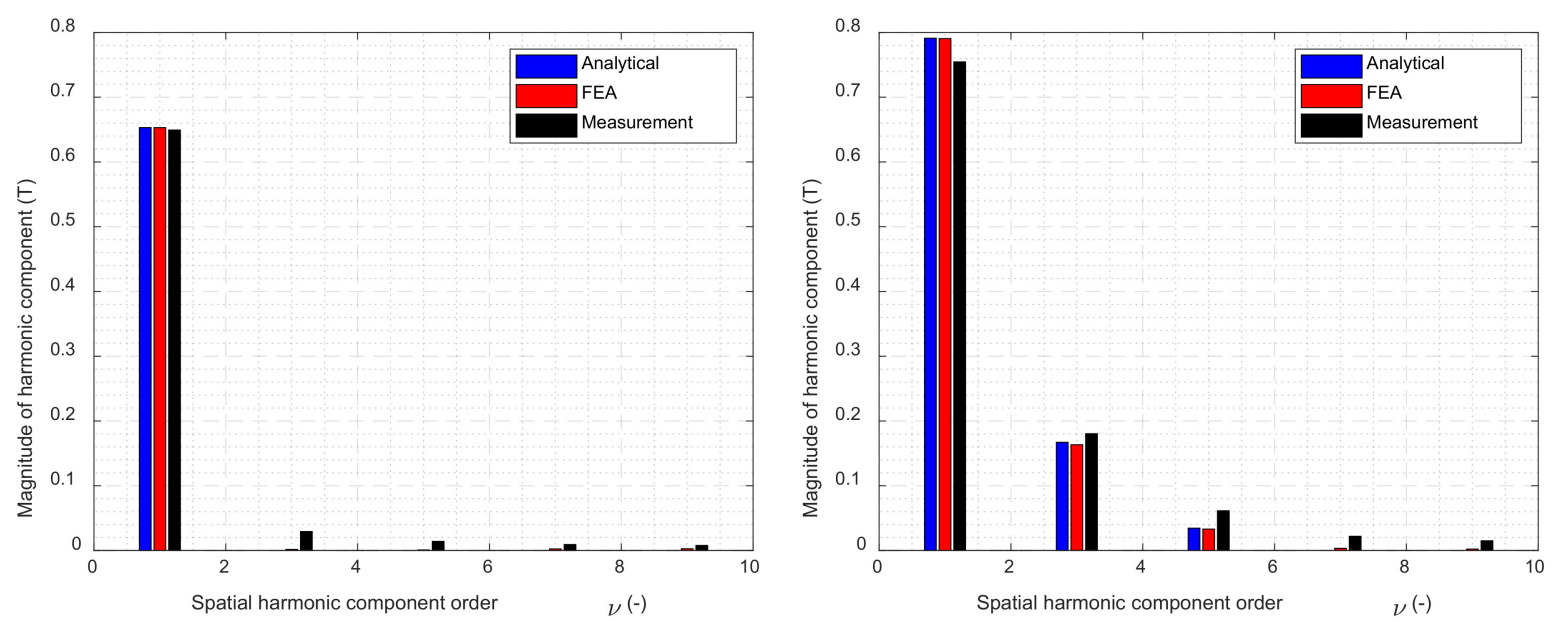

Figure 12. Spectrum of air gap magnetic flux density excited by single and higher order harmonic components injection obtained by analytical calculation, FEA, and measurement.

\section{Discussion}

The electromagnetic design of multiphase machines is subject to similar rules as the design of machines with a number of phases equal to three. However, the rules are modified generally to $m$-phases, and the consequences for the design can be different. The recommendations regarding the design of winding of multiphase machines and the effect of higher harmonic injection are summarized below.

The harmonic content of higher spatial harmonic components naturally decreases with an increase in the number of phases while the shortening of the coil pitch does not have as significant importance as in the case of three-phase windings. Together with the natural increase in the distribution factor, the decrease in the copper loss shown on a comparison of an example of a three-phase induction machine with $q=4$ and a short pitch coefficient of $\beta=5 / 6$ and a 12-phase winding with $q=1$ and a full coil pitch is $14.4 \%$. The obtained value is $5.6 \%$ more than the value calculated in [19] as a theoretical limit set by the usage of the distribution factor calculation only.

A separate chapter of the winding design are windings with an odd number of phases. A wrong choice of the number of slots per pole and phase can lead to the separation of the asymmetrical winding to several symmetrical windings with a different numbers of coils per phase.

An often-discussed topic of multiphase machines is the injection of higher harmonic components into the terminal voltage or input current. Except the effect to the control and the output characteristics of the machine, the higher harmonic injection also influences the equivalent circuit parameters, especially the inductances.

For every suitable harmonic component, the calculation of inductances is derived in (22) and (38), and the input current is calculated based on the known amplitude of the time harmonic components of the voltage. The machines can be viewed as a set of different machines with their own equivalent circuit parameters and supply voltages, which define their own torque characteristics until the saturation of the magnetic circuit can be neglected. If the saturation of the magnetic circuit is significant, the influence of all magnetic fields produced by different time harmonic components has to be involved in the calculation.

The only effect where the different time harmonic components cannot be separated is in the calculation of mutual inductances, which directly influence the correction factors of slot leakage inductance. The slot-related correction factors of multiphase windings are derived in [32], and the correct results are summarized in Table 2. We have then modified and generalized this approach to a multiphase machine under a higher harmonic injection.

The derived analytical calculations are validated by finite element analysis and the measurement of an experimental nine-phase induction motor under low saturation con- 
ditions. The inductances decrease with the square of the applied time harmonic, with an exception of the differential leakage inductance, which slightly increases.

Author Contributions: Conceptualization, K.H. and J.L.; methodology, R.C.; validation and measurement, R.C. and J.L.; writing—original draft preparation, J.L. and R.C.; writing-review and editing, K.H.; visualization, J.L.; supervision, K.H. All authors have read and agreed to the published version of the manuscript.

Funding: This research has been supported by the Ministry of Education, Youth and Sports of the Czech Republic under the project OP VVV Electrical Engineering Technologies with High-Level of Embedded Intelligence, CZ.02.1.01/0.0/0.0/18_069/0009855, and the funding program of the University of West Bohemia, number SGS 2021-021.

Institutional Review Board Statement: Not applicable.

Informed Consent Statement: Not applicable.

Data Availability Statement: Not applicable.

Conflicts of Interest: The authors declare no conflict of interest.

\section{References}

1. Salem, A.; Narimani, M. A Review on Multiphase Drives for Automotive Traction Applications. IEEE Trans. Transp. Electrif. 2019, 5, 1329-1348. [CrossRef]

2. Aselsan HVSM-285 Nine-Phase Permanent Magnet Motor. Available online: https://www.aselsan.com.tr/HVSM285_Permanent_ Magnet_Motor_For_HybridElectric_Vehicle_Applications_4348.pdf (accessed on 24 September 2021).

3. Aselsan HVSM-287 Nine-Phase Permanent Magnet Motor. Available online: https://www.aselsan.com.tr/HVSM287_Permanent_ Magnet_Synchronous_Motor_For_HybridElectric_Vehicle_Applications_3843.pdf (accessed on 24 September 2021).

4. Levi, E. Multiphase Electric Machines for Variable-Speed Applications. IEEE Trans. Ind. Electron. 2008, 55, 1893-1909. [CrossRef]

5. Duran, M.J.; Levi, E.; Barrero, F. Multiphase Electric Drives: Introduction; Wiley: Hoboken, NJ, USA, 2017; pp. 1-26. [CrossRef]

6. Kindl, V.; Cermak, R.; Ferkova, Z.; Skala, B. Review of Time and Space Harmonics in Multi-Phase Induction Machine. Energies 2020, 13, 496. [CrossRef]

7. Kong, W.; Qu, R.; Huang, J.; Kang, M. Air-Gap and Yoke Flux Density Optimization for Multiphase Induction Motor Based on Novel Harmonic Current Injection Method. In Proceedings of the 2016 XXII International Conference on Electrical Machines (ICEM 2016), Lausanne, Switzerland, 4-7 September 2016; pp. 100-106. [CrossRef]

8. Abdel-Khalik, A.S.; Masoud, M.I.; Ahmed, S.; Massoud, A.M. Effect of Current Harmonic Injection on Constant Rotor Volume Multiphase Induction Machine Stators: A Comparative Study. IEEE Trans. Ind. Appl. 2012, 48, 2002-2013. [CrossRef]

9. Wang, J.; Qu, R.; Zhou, L. Dual-Rotor Multiphase Permanent Magnet Machine with Harmonic Injection to Enhance Torque Density. IEEE Trans. Appl. Supercond. 2012, 22, 5202204. [CrossRef]

10. De Gaetano, D.; Harikumaran, J.; Sala, G.; Degano, M.; Buticchi, G.; Gerada, C. On Torque Improvement by Current Harmonic Injection in Isotropic and Anisotropic Multi-Phase Machines. IEEE J. Emerg. Sel. Top. Ind. Electron. 2021, 2. (Early Access). [CrossRef]

11. Abdel-Khalik, A.S.; Daoud, M.I.; Ahmed, S.; Elserougi, A.A.; Massoud, A.M. Parameter Identification of Five-Phase Induction Machines with Single Layer Windings. IEEE Trans. Ind. Electron. 2014, 61, 5139-5154. [CrossRef]

12. Wang, P.; Zheng, P.; Sui, Y.; Wu, F.; Cheng, L.; Li, T. Design and Analytical Inductance Calculations of Five-Phase Fault-Tolerant Permanent-Magnet Machine. In Proceedings of the 2014 17th International Conference on Electrical Machines and Systems (ICEMS), Hangzhou, China, 22-25 October 2014; pp. 1639-1642. [CrossRef]

13. Wang, D.; Wu, X.; Chen, J.; Guo, Y.; Cheng, S. A Distributed Magnetic Circuit Approach to Analysis of Multiphase Induction Machines with Nonsinusoidal Supply. IEEE Trans. Energy Convers. 2015, 30, 522-532. [CrossRef]

14. Akay, A.; Lefley, P. Torque Ripple Reduction Method in a Multiphase PM Machine for No-Fault and Open-Circuit Fault-Tolerant Conditions. Energies 2021, 14, 2615. [CrossRef]

15. Spas, S.; Kowarschik, S.; Laumer, J.; Wiesinger, M.; Hackmann, W. Five-Phase IPMSM: Torque Density Improvement by Third Harmonic Injection. In Proceedings of the 020 International Symposium on Power Electronics, Electrical Drives, Automation and Motion (SPEEDAM), Sorrento, Italy, 24-26 June 2020; pp. 779-786. [CrossRef]

16. Riveros, J.A.; Yepes, A.G.; Barrero, F.; Doval-Gandoy, J.; Bogado, B.; Lopez, O.; Jones, M.; Levi, E. Parameter Identification of Multiphase Induction Machines with Distributed Windingspart 2: Time-Domain Techniques. IEEE Trans. Energy Convers. 2012, 27, 1067-1077. [CrossRef]

17. Caruso, M.; Di Tommaso, A.O.; Marignetti, F.; Miceli, R. A General Investigation on the Differential Leakage Factor for Symmetrical and Asymmetrical Multiphase Winding Design. Energies 2020, 13, 5414. [CrossRef]

18. Heller, B.; Hamata, V. Harmonic Field Effects in Induction Machines; Elsevier: Amsterdam, The Netherlands, 1977; p. 330, ISBN 044499856X. 
19. Levi, E.; Bojoi, R.; Profumo, F.; Toliyat, H.A.; Williamson, S. Multiphase Induction Motor Drives-A Technology Status Review. IET Electr. Power Appl. 2007, 1, 489-516. [CrossRef]

20. Grandi, G.; Sanjeevikumar, P.; Casadei, D. Preliminary Hardware Implementation of a Six-Phase Quad-Inverter Induction Motor Drive. In Proceedings of the 2011 14th European Conference on Power Electronics and Applications, Birmingham, UK, 30 August-1 September 2011; pp. 1-9.

21. Godwin, G.L. Dynamoelectric Machines for Multiples of Three Phases with Unbalanced Fractional-Slot Windings. U.S. Patent No. US4409507A, 11 October 1983.

22. Khutoretsky, G.M.; Vorontsov, A.I.; Drozdova, L.A.; Yanik, B.S. Six-Phase Winding of Electric Machine Stator. U.S. Patent No. US4132914A, 2 January 1979.

23. Hamilton, D.C.; Fleming, J.W. Dual, Three Phase, Inverter-Driven Motor. U.S. Patent No. US4220881A, 2 September 1980.

24. Sui, Y.; Zheng, P.; Fan, Y.; Zhao, J. Research on the Vector Control Strategy of Five-Phase Permanent-Magnet Synchronous Machine Based on Third-Harmonic Current Injection. In Proceedings of the 2017 IEEE International Electric Machines and Drives Conference (IEMDC), Miami, FL, USA, 21-24 May 2017. [CrossRef]

25. Pyrhonen, J.; Jokinen, T.; Hrabovcova, V. Design of Rotating Electrical Machines, 2nd ed.; John Wiley \& Sons Ltd: Chichester, UK, 2013; p. 612, ISBN 978-1-118-58157-5.

26. Vaske, P.; Riggert, J.H. Streuung umlaufender Maschinen (Leakage of rotating machines). In Elektrische Maschninen und Umformer, Teil 2. Berechnung Elektrischer Maschinen (Electrical Machines and Convertors, Part 2: Calculations of Electric Machinery), 7th ed.; B.G. Teubner: Stuttgart, Germany, 1967; pp. 50-58.

27. Müller, G.; Vogt, K.; Ponick, B. Streuung (Leakage). In Berechnung Elektrischer Maschinen (Calculations of Electric Machinery); Wiley-Vch: Weihein, Germany, 2007; pp. 295-343, ISBN 978-3527405251.

28. Boldea, I.; Nasar, S.A. Leakage inductances and resistances. In Induction Machine Handbook; CRC Press: Boca Raton, FL, USA 2002; pp. 133-158, ISBN 0-8493-004-5.

29. Laksar, J. Improved Calculation of the Slot Leakage Inductance of Different Slot Shapes. Electr. Eng. 2020, 102, 1129-1139. [CrossRef]

30. Madariaga, C.; Jara, W.; Tapia, J.A.; Pyrhönen, J.; Lindh, P.; Riedemann, J.A. Closed-Form Solution for the Slot Leakage Inductance of Tooth-Coil-Winding Permanent Magnet Machines. IEEE Trans. Energy Convers. 2019, 34, 1572-1580. [CrossRef]

31. Liwschitz-Garik, M.; Whipple, C. Electric Machinery, Vol. 2: A-C Machines; Van Nostrand Company, Inc.: New York, NY, USA, 1946.

32. Cordovil, P.; Chabu, I.E. Analytical Calculation of Slot Leakage Inductance in Multiphase Electrical Machines. In Proceedings of the 2016 22th International Conference on Electrical Machines (ICEM), Lausanne, Switzerland, 4-7 September 2016; pp. 1352-1358. [CrossRef]

33. Kalaj, P.; Cermak, R.; Frank, Z.; Kindl, V.; Komrska, T.; Laksar, J.; Peroutka, Z. Measurement of the Effects of Higher Harmonic Injection on Nine-Phase Induction Motor. In Proceedings of the IECON 2020 The 46th Annual Conference of the IEEE Industrial Electronics Society, Singapore, 18-21 October 2020; pp. 4851-4856. [CrossRef] 